\title{
Design and rationale of a nationwide screening analysis from the LIPIDOGRAM2015 and LIPIDOGEN2015 studies
}

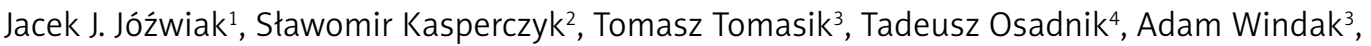
Krzysztof Studziński ${ }^{3}$, Mirosław Mastej ${ }^{5}$, Alberico Catapano ${ }^{6}$, Kausik K. Ray ${ }^{7}$, Dimitri P. Mikhailidis ${ }^{8}$, Peter P. Toth ${ }^{9}$, George Howard ${ }^{10}$, Gregory Y. H. Lip ${ }^{11}$, Maciej Tomaszewski ${ }^{12}$, Fadi J. Charchar ${ }^{13}$, Naveed Sattar ${ }^{14}$, Bryan Williams ${ }^{15}$, Thomas M. MacDonald ${ }^{16}$, Paweł Krzemień ${ }^{17}$, Michał Dobrakowski ${ }^{2}$, Aleksandra Kasperczyk ${ }^{2}$, Dariusz Nowak ${ }^{18}$, Łukasz Skowron ${ }^{19}$, Żaneta Żak ${ }^{1}$, Joanna Lewek ${ }^{20}$, Maciej Banach ${ }^{20,21,22}$ on behalf of the LIPIDOGRAM2015 and LIPIDOGRAM2015 Investigators ${ }^{\star *}$

${ }^{1}$ Department of Family Medicine and Public Health, Faculty of Medicine, University of Opole, Opole, Poland

2Department of Biochemistry, Faculty of Medical Sciences in Zabrze,

Medical University of Silesia in Katowice, Poland

${ }^{3}$ Chair of Family Medicine, Jagiellonian University Medical College, Krakow, Poland

${ }^{4}$ Department of Pharmacology, Faculty of Medical Sciences in Zabrze,

Medical University of Silesia in Katowice, Poland

${ }^{5}$ Mastej Medical Centre, Jasło, Poland

${ }^{6}$ Department of Pharmacological Sciences University of Milano and Multimedica IRCCS, Milano, Italy

${ }^{7}$ Imperial Centre for Cardiovascular Disease Prevention, Department of Primary Care and Public Health, Imperial College, Kensington, London, UK

${ }^{8}$ Department of Clinical Biochemistry, Royal Free Hospital, University College London, London, UK

${ }^{9}$ Cicarrone Center for the Prevention of Cardiovascular Disease, Johns Hopkins University School of Medicine, Baltimore, Maryland, and CGH Medical Center, Sterling, Illinois, USA

${ }^{10}$ Department of Biostatistics, School of Public Health of Alabama, Birmingham, AL, USA

${ }^{11}$ Liverpool Centre for Cardiovascular Science, University of Liverpool and Liverpool Heart \& Chest Hospital, Liverpool, United Kingdom; and Aalborg Thrombosis Research Unit, Department of Clinical Medicine, Aalborg University, Aalborg, Denmark

${ }^{12}$ Division of Cardiovascular Sciences, Faculty of Biology, Medicine and Health, University of Manchester, Manchester, UK

${ }^{13}$ School of Health and Life Sciences, Federation University Australia, Ballarat, Victoria, Australia

${ }^{14}$ Institute of Cardiovascular and Medical Science, University of Glasgow, Glasgow, UK

${ }^{15} \mathrm{NIHR}$ University College London Biomedical Research Centre, University College London and University College London Hospitals NHS Foundation Trust, London, UK ${ }^{16}$ MEMO Research, University of Dundee, Ninewells Hospital and Medical School, Dundee DD1 9SY, UK

${ }^{17}$ Euroimmun Polska Sp. z o.o., Poland

${ }^{18}$ Municipal Hospital, Czestochowa, Poland

${ }^{19}$ Department of Gastroenterology and Internal Diseases, Military Institute of Medicine, Warsaw, Poland

${ }^{20}$ Polish Mothers Memorial Hospital Research Institute, Lodz, Poland

${ }^{21}$ Department of Hypertension, Chair of Nephrology and Hypertension, Medical University of Lodz, Lodz, Poland

${ }^{22}$ Cardiovascular Research Centre, University of Zielona Gora, Zielona Gora, Poland

\section{Corresponding authors:}

Prof. Jacek J. Jóźwiak MD, PhD

Department of

Family Medicine and

Public Health

Faculty of Medicine

University of Opole

48 Oleska St

45-052 Opole, Poland Phone: +48774527557

Fax: +48 774527557

+48 774527557

E-mail: jacek.jozwiak.1234@ gmail.com

Prof. Maciej Banach MD, PhD, FNLA, FAHA, FESC, FASA

Department of Hypertension WAM University Hospital Medical University of Lodz 113 Zeromskiego St 90-549 Lodz, Poland Phone: +48 426393771 Fax: +48 426393771 E-mail: maciej.banach@ icloud.com

Submitted: 17 May 2020; Accepted: 24 May 2020

Online publication: 4 June 2020

Arch Med Sci 2022; 18 (3): 604-616

DOI: https://doi.org/10.5114/aoms.2020.96052

Copyright $\odot 2020$ Termedia \& Banach 


\section{Abstract}

Introduction: Cardiovascular disease (CVD) is a major cause of morbidity and mortality throughout the world. The LIPIDOGRAM2015 study was performed to estimate the prevalence of risk factors for atherosclerotic diseases as well as cardiovascular and related disorders in the primary care setting in Poland. The LIPIDOGEN2015 sub-study was designed to include a random cohort of patients in order to analyse parameters related to lipid metabolism, oxidative stress, inflammatory responses, autoimmune disorders, and gene variants that confer susceptibility to cardiometabolic and atherosclerotic diseases.

Material and methods: The recruitment was carried out by 438 primary care physicians in Poland. The expected number of patients recruited for the LIPIDOGRAM2015 study was 13,000-14,000 with 13-15\% (1700-2000) also participating in the LIPIDOGEN2015 sub-study. Each patient had to complete a questionnaire concerning medical and family history, concomitant diseases, and pharmacotherapy. Anthropometric measurements were performed at the doctor's office. For the LIPIDOGEN2015 sub-study, saliva samples for DNA isolation and blood samples for measurement of glycated haemoglobin, oxidative stress parameters, autoantibody levels, and inflammatory cytokine profile and apolipoprotein profile were collected. Follow-up data will be obtained from the National Health Fund in Poland.

Results: The LIPIDOGRAM2015 and LIPIDOGEN2015 study cohort reflects the prevalence of cardiovascular risk factors and concomitant diseases, markers of oxidative stress, the presence of autoantibodies, inflammatory cytokine profile, and apolipoprotein profile, as well as genetic variants potentially conferring susceptibility to cardiometabolic and atherosclerotic diseases.

Conclusions: This study presents the prevalence of different CV risk factors, with special emphasis on lipid disorders, and it assesses the relationship between inflammation, oxidative stress, and mutations in genes encoding proteins regulating lipid metabolism, as well as genes conferring susceptibility to cardiovascular, cardiometabolic, and related diseases.

Key words: cardiovascular diseases, cardiometabolic diseases, atherosclerosis, dyslipidaemia, inflammation, oxidative stress, genes.

\section{Introduction}

Cardiovascular disease (CVD) accounts for an enormous burden of morbidity and mortality throughout the world. Classic CVD risk factors contributing to the development of atherosclerotic CVD (ASCVD) include hypertension, diabetes mellitus, dyslipidaemia, smoking, and obesity. The presence of these risk factors leads to endothelial dysfunction and oxidative stress, which contribute to the pathophysiological processes of atherosclerosis [1-4]. Between 1962 and 2015, there were over a dozen epidemiological studies conducted in Poland, which concerned cardiovascular risk factors, and except for the LIPIDOGRAM studies, they did not relate specifically to patients attending primary health care (PHC).

The previous LIPIDOGRAM cohort studies (2004, 2006, 2010) showed the distribution of cardiovascular risk factors throughout 6 years in an adult population representative of patients attending PHC in Poland, as well as the efficacy of hypercholesterolaemia treatment with more than 2-year follow-up, and a series of studies on obesity in relation to other cardiovascular risk factors and coronary artery diseases (CAD) [5-7]. The current edition of the LIPIDOGRAM study updates the data on cardiovascular risk factors in the PHC setting, for the first time investigates the prevalence of familial hypercholesterolaemia, gives more details on the therapy, and gives an insight into the pathophysiology of coronary artery disease by an- alysing oxidative stress, autoantibodies, and gene variants conferring susceptibility to ASCVD.

Oxidative stress is the result of an imbalance between reactive oxygen species (ROS) production and utilisation. ROS are reactive intermediates of molecular oxygen. Under physiological conditions, they are formed in cells as byproducts of cellular metabolism and act as important second messengers that transduce intracellular signals involved in various biological process. Many factors can induce ROS generation, such as ultraviolet radiation, smoking, alcohol consumption, exposure to pollutants, or microbial infection resulting in a respiratory burst. When overproduction of ROS exceeds the buffering capacity of the antioxidant defence systems or when antioxidants are defective, oxidative stress occurs, resulting in oxidative damage to lipids, deoxyribonucleic acid (DNA), and carbohydrates [3]. Increased levels of ROS have been reported in several diseases, including atherosclerosis, CVD, neurodegenerative disorders, cancer, renal diseases, pulmonary diseases, and cardiometabolic diseases [8].

Excessive production of ROS and the insufficiency of enzymatic and non-enzymatic defence mechanisms lead to the oxidation of low-density lipoprotein (LDL) and a decrease in the bioavailability of nitric oxide (NO) in endothelial cells, which begin to release the pro-inflammatory cytokines and express adhesion molecules, such as tumour necrosis factor $\alpha$ (TNF- $\alpha$ ), interleukin-6 (IL-6), monocyte chemoattractant protein-1 (MCP-1), 
and intercellular adhesion molecule-1 (ICAM-1) These mediators promote adhesion and infiltration of monocytes, production of foam cells, growth of smooth muscle or endothelial cells, and increased activity of matrix metalloproteinases. All of these pathophysiological processes potentiate endothelial dysfunction and atheromatous plaque formation in conjunction with impaired lipid metabolism. On the other hand, pro-inflammatory cytokines may lead to increased release of ROS maintaining a positive feedback loop. Additionally, the accumulation of oxidative protein and lipid damage may induce the production of antibodies directed against altered proteins of the body [9-15].

Autoimmune diseases (AD) are disorders in which the immune response to self-antigens results in damage or dysfunction of tissues with a very diverse clinical picture and complicated pathogenetic mechanisms. AD can be systemic or can affect specific organs, cell types, and body systems [16]. Thus far, the aetiology of autoantibody (AAB) formation has not been fully understood. There are many suspected factors that increase the risk of $A A b$ production, including genetic predisposition and environmental factors such as infections, oxidative stress factors, physical and chemical agents, as well as stressful life events [1, 17-20]. In addition to well-known AAb, such as antinuclear antibodies (ANA) or anti-cyclic citrullinated peptides (anti-CCP), some lesser-investigated $A A b$, such as antibodies against citrullinated forms of enolase (CEP-1 $\alpha$ ) and dense fine speckled 70 antigen (DSF70), may also be associated with cardiometabolic diseases [18]. On the other hand, increased mortality due to CVD in patients with recognised rheumatoid arthritis and systemic lupus erythematosus confirms that inflammation and oxidative stress promote their development $[8,9,21]$. The role of inflammation in the pathogenesis of atherosclerosis and diabetes mellitus is well documented [22]. In light of the above, it is postulated that the parameters characterising both processes may serve as biomarkers of cardiovascular risk. In this context, the role of C-reactive protein (CRP, or high-sensitivity CRP (hsCRP)) or certain proinflammatory cytokines is well documented [23]. However, the potential significance of markers associated with oxidative stress (especially enzymatic), antinuclear antibodies (ANA), and anti-citrullinated protein/peptide antibodies (ACPA) have not yet been determined. Despite the wide body of evidence implicating inflammation, oxidative stress, and the activity of ROS in animal models of CVD, the exact mechanisms involved in the pathogenesis of CVD are still not fully understood.

CVD, stroke, diabetes mellitus, and metabolic syndrome are a result of complex interplay be- tween genetic and environmental factors. On one hand, detrimental dietary habits may run in families [24], and on the other hand, there is a clear genetic susceptibility to obesity and different cardiometabolic diseases [25-27]. Polygenic risk scores for developing CVD and diabetes are extensively studied with promising results $[28,29]$, although only by analysing large quantities of data from different populations can such scores be properly validated.

Based on the abovementioned, the main aim of The LIPIDOGRAM2015 and LIPIDOGEN2015 study - a nationwide study of cardiovascular health in primary care in Poland - was to estimate the prevalence of risk factors of atherosclerotic cardiovascular disease, frequency of cardiovascular and related disorders, and their treatment in the primary care setting of Poland. Additionally, a substudy, LIPIDOGEN2015, was planned, which comprised up to $15 \%$ of randomly selected recruited patients and was designed to analyse parameters related to lipid metabolism, atherosclerosis, oxidative stress, inflammatory responses, autoimmune disorders, and gene variants that confer susceptibility to CVD and cardiometabolic diseases.

\section{Material and methods}

\section{Design}

A nationwide cross-sectional study, LIPIDOGRAM2015, was carried out in Poland in the fourth quarter of 2015 and the first and second quarters of 2016.

\section{Setting}

A group of 700 physician-investigators working in public or private primary health care practices were randomly selected by the principal investigators from the Medical Data Management database using computer software. The group of 700 physician-investigators was selected in a manner proportional to the number of inhabitants in a given administrative region (a so-called voivodeship). It was assumed that each physician-investigator would include at least 30 patients under his/ her medical care in the study. To reach the required sample size representative for all administrative regions in Poland, the number of patients included in the survey in the smallest Polish voivodeship (Lubuskie voivodeship $-2.64 \%$ of the population of Poland) should not be lower than 550 people. Finally, a total of 438 physicians in 398 practices in 16 major administrative regions were recruited.

\section{Participants}

Between October 2015 and June 2016, a total of selected primary care physicians actively en- 
rolled consecutive primary care patients (age $\geq 18$ years, who were under the care of a physician-investigator during the recruitment period) who sought medical care for any medical reason in primary health care practices. All patients were of Caucasian Polish ethnicity. Prior to data collection, each physician-investigator undertook individual training related to the study procedure and methodology as described in the LIPIDOGRAM2015 and LIPIDOGEN2015 Protocol. The main exclusion criteria were dementia/mental disease resulting in an inability to provide informed consent or lack of consent to participate in the study (Table I).

\section{Measurements}

For each patient recruited for the study, a 28item questionnaire gathered data on chronic diseases and their treatment, lifestyle (diet, physical activity, smoking status), and family history of CVD (altogether 24 questions). The questionnaire also recorded demographic data: age, sex, place of residence, and level of education (altogether four questions). The questionnaire was first validated in a group of 10 primary care physicians who did not submit comments or noted difficulties in completing it. The content validity was checked by comparing the questionnaire with other similar tools used in Poland (the English translation of the questionnaire is shown in Appendix S1). Each questionnaire was labelled with an individual barcode, identical to barcodes on samples of blood and saliva. A nine-digit code was used - the first digit indicated the edition of the LIPIDOGRAM study (in this case the number 3 indicates year 2015), the next two digits were identical to the code of the district accordingly to National Health Fund (01-16), the next two digits were identical to the code of the physician-investigator in a given district (0-99), and the last four digits indicated the patient number for a given physician-investigator (0001-0030). Data from the paper version of the questionnaire was scanned using a handwriting recognition program. Data of biochemical assays was electronically transferred directly from a biochemical analyser to the appropriate electronic records of the study participant using the nine-digit code mentioned above.

For all patients, anthropometric measurements were made (height, body weight, waist circumference, and hip circumference). Height and weight measurements were carried out without heavy clothing or shoes. The BMI was calculated based on the height measurements in metres and body mass measurements in kilograms $\left[\mathrm{kg} / \mathrm{m}^{2}\right]$. Waist circumference was measured over the unclothed abdomen at the level of the midpoint between the lower margin of the ribs and the anterior superior iliac crest spine. The hip circumference was measured at the level of the greater trochanters. In all enrolled patients serum samples were obtained after $12 \mathrm{~h}$ or more of fasting. On the same day, measurements of blood pressure, heart rate, and fasting glucose were taken as well as lipid profile samples. Additionally, in a subgroup of patients (LIPIDOGEN2015 sub-study), saliva samples for DNA isolation and additional blood samples for measurement of glycated haemoglobin concentration, oxidative stress parameters, autoantibody levels, inflammatory cytokine profile, and apolipoprotein profile were collected (Figure 1).

\section{Clinical chemistry}

The collected blood samples were transferred in cooled containers to a central laboratory (Silesian Analytical Laboratories - SLA in Katowice, Poland). The laboratory meets appropriate International Organisation for Standardisation (ISO) and Good Laboratory Practice (GLP) standards and also reg-

Table I. Eligibility criteria for the LIPIDOGRAM2015 and LIPIDOGEN2015 studies

\begin{tabular}{|l|}
\hline Inclusion criteria (all of them apply) \\
\hline 1. Individuals over 18 years old, who are under the care of physician-investigator in a primary care clinic \\
\hline $\begin{array}{l}\text { 2. Individuals voluntarily seeking medical assistance for any medical reason in the } 4^{\text {th }} \text { quarter of } 2015 \text { or } 1^{\text {st }} \text { and } \\
2^{\text {nd }} \text { quarter of } 2016\end{array}$ \\
\hline $\begin{array}{l}\text { 3. Individuals who give voluntary written consent to participate in the study, permission to use anonymous } \\
\text { questionnaire data and the results of laboratory tests, secured biologic material for the purpose of statistical } \\
\text { and scientific studies, and who declare their willingness to continue participation in the following years }\end{array}$ \\
\hline Exclusion criteria (one or more of the following) \\
\hline 1. Full or partial legal incapacitation of study participants \\
\hline $\begin{array}{l}\text { 2. Lack of consent for the collection of blood/saliva and the use of anonymous questionnaire data and the results } \\
\text { of laboratory tests for statistical and scientific purposes }\end{array}$ \\
\hline $\begin{array}{l}\text { 3. Intention to change the place of residence in the near future, which precludes continuation of the study and any } \\
\text { other circumstances and information about participants that, in the opinion of the physician-investigator, can } \\
\text { adversely affect their participation in the following years }\end{array}$ \\
\hline
\end{tabular}




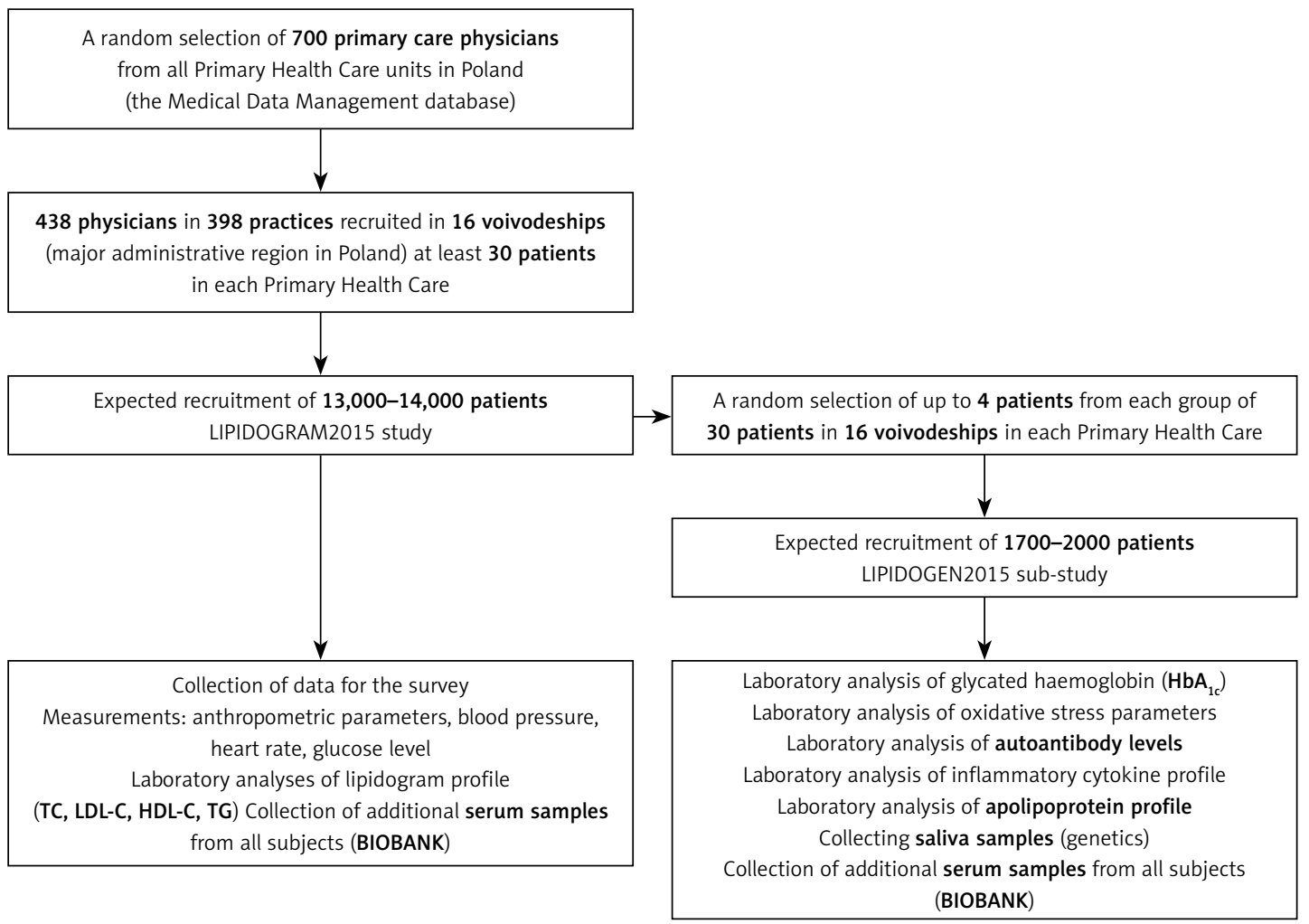

Figure 1. LIPIDOGRAM2015 and LIPIDOGEN2015 flowchart

ularly undergoes internal, external, and international audits. Measurements of total cholesterol (TC), triglycerides (TG), high-density lipoprotein cholesterol (HDL-C), and low-density lipoprotein cholesterol (LDL-C) (with direct immunological measurement) were performed and carried out using the same methodology and the same Siemens Advia 1800 analyser and Siemens reagents (Munich, Germany), within $12 \mathrm{~h}$ of obtaining the blood sample. Fasting glycaemia was measured using Bionime glucometers (Taichung City, Taiwan) and Rightest strip tests (Taichung City, Taiwan). $\mathrm{HbA}_{1 \mathrm{c}}$ was assessed using high-performance liquid chromatography (HPLC) performed by Variant II Turbo (Bio-Rad, Hercules, California, USA).

\section{Oxidative stress measurement}

For the evaluation of oxidative stress intensity, the indices of free-radical damage to lipids and proteins, enzymatic and non-enzymatic antioxidant system parameters in serum, and erythrocytes were measured. In serum, indices of free-radical damage to lipids and proteins include the following: total oxidant capacity (TOC) [30], lipid hydroperoxides (LPH) [31], lipofuscin (LPS) [32], and protein thiol groups [33] (PSH), and malondialdehyde (MDA) [34] concentration. The activity of serum superoxide dismutase (SOD) [35] was also determined. Additionally, the parameters of a non-enzymatic antioxidant system, such as total antioxidant status (TAS) [36], the concentration of ceruloplasmin (CER) [37], albumin, bilirubin, and uric acid (UA) were determined. Based on TOC and TAS values, the oxidative stress index (OSI) was calculated. In erythrocytes, the indices of free-radical damage to lipids and proteins, such as LPS and MDA, were determined. The analysis included also the activities of SOD [35], catalase (CAT) [38], and the enzymes related to glutathione metabolism, such as glutathione peroxidase (GPx) [39], glutathione-S-transferase (GST) [40], and glutathione reductase (GR) [37].

\section{Autoantibody assessment}

Anti-nuclear (ANA) antibodies were detected by indirect immunofluorescence on human laryngeal carcinoma cells (HEp-2) with commercially available Euroimmun Medizinische Labordiagnostika AG (Lübeck, Germany) test kits (Mosaic Basic Profiles 3; catalogue number FC 1800-2010-3). Sample incubations were carried out manually, according to the instructions included in the test kit. The results were evaluated on a EUROstar III fluorescence microscope (CarlZeiss Oberkochen, Germany). The test result includes a qualitative assessment of the presence of ANA antibodies, estimation of antibody titre, and determination of the characteristic pattern according to the ICAP (International Consensus on Antinuclear Antibody Pattern) nomenclature. The concentrations of anti-DFS70, CCP, 
and CEP1- $\alpha$ antibodies were determined by ELISA method. We used commercially available Euroimmun Medizinische Labordiagnostika AG (Euroimmun AG, Lübeck, Germany) test kits. Incubation were performed automatically with a Euroimmun Analyzer I (Euroimmun AG, Lübeck, Germany) according to the instructions included in the test kit.

\section{Apolipoproteins and inflammatory markers}

We also assumed that for the evaluation of inflammatory response and apolipoprotein levels in serum the Bio-Plex Pro Human Apolipoprotein Assay Panel and Bio-Plex Pro Human Inflammation Panel (Bio-Rad, Hercules, California, USA) will be used. Concentrations of apolipoproteins, such as Apo A1, Apo A2, Apo B, Apo C1, Apo C3, Apo $D$, Apo E, Apo $H$, and Apo J, will be determined. The analysis of biomarkers of inflammation will include: C-reative protein (CRP), Treg cytokines (IL-2, IL-10, IL-12, IL-19, IL-20, IL-22, IL-26, IL-27, IL-35, and interferon (IFN)- $\lambda 2$ and IFN- $\lambda 1$ ), matrix metalloproteinases (MMP-1, MMP-2, MMP-3), tumour necrosis factor (TNF) superfamily proteins, and IFN family proteins (APRIL/TNFSF13, BAFF/ TNFSF13B, SCD30/TNFRSF8, SCD163, chitinase3-like 1, gp130/sIL-6R $\beta$, IFN- $\alpha 2$, IFN- $\beta$, IFN- $\gamma$, sIL-6R $\alpha$, IL-8, IL-11, IL-32, IL-34, LIGHT/TNFSF14, osteocalcin, osteopontin, pentraxin-3, sTNF-R1, STNF-R2, TSLP, and TWEAK/TNFSF12).

\section{Genetic analyses}

Two-millilitre saliva samples were collected according to the manufacturer's instructions for the Oragene-DNA / OG-500 kit (DNA Genotek, Ottawa, Canada). Saliva was collected and banked according to the manufacturer's instructions until DNA isolation. Isolation of banked saliva will be carried out using the PrepIT-L2P kit (DNA Genotek, Ottawa, Canada) according to the manufacturer's protocol. In the next step, quantitative and qualitative analyses will be carried out by a combination of agarose gel electrophoresis and spectrophotometry (concentration measurement and absorbance ratio 260/280).

In order to identify gene variants related to lipid disorders and/or associated with susceptibility to metabolic syndrome, hypertension, diabetes mellitus, CAD, and autoimmune diseases we will use custom panels including known and candidate genes associated with the above-mentioned diseases. The reaction will be performed on the MiSeq sequencer (Illumina, San Diego, USA) based on sequencing technologies by synthesis. The results from the sequencing will be analysed using the commercial software Variant Studio v3.0 (Illumina, San Diego, USA) as well as online tools.

\section{Follow-up data}

Follow-up data on all-cause mortality, cardiovascular outcomes, and hospitalisations will be obtained from the National Health Fund, which is an obligatory nationwide health insurance institution.

\section{Ethical approval}

All individuals signed an informed consent form to participate in the study and gave their permission to use anonymous questionnaire data, the results of their laboratory tests, and secured biological material for the purpose of statistical and scientific studies. The LIPIDOGRAM2015 and LIPIDOGEN2015 studies received a positive opinion from the Bioethical Commission of the Chamber of Physicians on 02/12/2015 (No. K.B.Cz.-0018/2015) and conform to the principles outlined in the Declaration of Helsinki.

\section{Statistical analysis}

Analysis will be performed with R [41] and Statistica 13.3 software (StatSoft, Tulsa). Data will be expressed as mean \pm SD (for normal distribution) and median (nonparametric distribution) for continuous variables, and as a percentage for categorical variables. Univariate comparison of markers related to autoimmune diseases according to clinical variables will be performed using the U-Mann-Whitney method for nonparametric variables or $\chi^{2}$ test/Fisher exact test where appropriate. Spearman correlations for categorical variables will be performed to evaluate relationships between autoimmune diseases and laboratory tests as well as other parameters. Uni- and multivariate logistic regression analyses will be used to determine the association between clinical and genetic variables and abnormal parameters of oxidative stress. Additionally, due to the large number of variables, dimensionality reduction techniques might be used in some analyses. A two-sided $p<0.05$ will be considered statistically significant, and in case of genetic analysis the Bonferroni correction or false discovery rate will be applied.

\section{Results}

\section{The study summary for patients}

At the conclusion of the LIPIDOGRAM2015 and LIPIDOGEN2015 studies, each enrolled participant received his/her test results with an interpretation made by a physician-investigator, along with a non-promotional book promoting healthy lifestyle.

\section{Baseline characteristics}

The clinical characteristics of the LIPIDOGRAM2015 and LIPIDOGEN2015 study cohort will 
reflect the frequency of occurrence of cardiovascular risk factors and concomitant diseases and will include all of the variables listed in Table II. Additionally, the lipid profile and glucose level will be presented. For the LIPIDOGEN2015 sub-study, $\mathrm{HbA}_{1 \mathrm{c}}$ data will be available (Table III).

\section{Autoantibody assessment}

The occurrence of tested autoantibodies will be assessed in the context of concomitant diseases oxidative stress parameters and genes related to autoimmune disorders, as well as long-term prognosis.

\section{Oxidative stress}

Parameters of oxidative stress will be correlated with baseline clinical characteristics as well as the concentrations of different fractions of apolipoproteins, markers of inflammation, and the presence of autoantibodies.

\section{Apolipoprotein and inflammatory cytokine profile}

We will aim to correlate apolipoprotein and inflammatory cytokine profiles with the presence of atherosclerotic diseases, treatment of dyslipidaemia, as well as long-term prognosis in patients with hypertension, diabetes, etc.

\section{Genetic data}

Mutations and common variants allegedly conferring susceptibility to CVD and cardiometabolic diseases will be correlated with the presence of

Table II. Anthropometric and clinical data obtained from enrolled patients of the LIPIDOGRAM2015 and LIPIDOGEN2015 studies

\begin{tabular}{|c|c|c|c|}
\hline \multicolumn{4}{|l|}{ Sociodemographic data } \\
\hline Age & Gender & Level of education & Place of residence \\
\hline \multicolumn{4}{|c|}{ Anthropometric data and physical examination } \\
\hline Height $[\mathrm{cm}]$ & Weight [kg] & Waist $[\mathrm{cm}]$ & Hip $[\mathrm{cm}]$ \\
\hline Blood pressure [mmHg] & Heart rate $[\mathrm{bpm}]$ & & \\
\hline \multicolumn{4}{|l|}{ Lifestyle } \\
\hline Physical activity & Diet & Tobacco use & Alcohol intake \\
\hline \multicolumn{4}{|l|}{ Concomitant diseases } \\
\hline $\begin{array}{l}\text { Family history of CVD } \\
\text { diseases }\end{array}$ & Coronary heart disease & Myocardial infarction & Atrial fibrillation \\
\hline Ischemic stroke & Haemorrhagic stroke & & \\
\hline $\begin{array}{l}\text { Familial } \\
\text { hypercholesterolemia }\end{array}$ & Dyslipidaemia & Diabetes mellitus & \\
\hline Hypertension & Chronic kidney disease & & \\
\hline \multicolumn{4}{|l|}{ Pharmacotherapy } \\
\hline Treatment of dyslipidaemia & $\begin{array}{c}\text { Treatment of diabetes } \\
\text { mellitus }\end{array}$ & $\begin{array}{l}\text { Treatment of } \\
\text { hypertension }\end{array}$ & \\
\hline Antiplatelet treatment & $\begin{array}{l}\text { Anticoagulation } \\
\text { treatment }\end{array}$ & & \\
\hline
\end{tabular}

Table III. Laboratory tests performed in the LIPIDOGRAM2015 and LIPIDOGEN2015 studies

\begin{tabular}{|c|c|c|c|}
\hline \multicolumn{4}{|c|}{ LIPIDOGRAM2015 \& LIPIDOGEN2015 } \\
\hline $\mathrm{TC}[\mathrm{mg} / \mathrm{dl}]$ & $\mathrm{HDL}[\mathrm{mg} / \mathrm{dl}]$ & LDL [mg/dl] & $\mathrm{TG}[\mathrm{mg} / \mathrm{dl}]$ \\
\hline \multicolumn{4}{|l|}{ Glucose $[\mathrm{mg} / \mathrm{dl}]$} \\
\hline \multicolumn{4}{|l|}{ LIPIDOGEN2015 sub-study } \\
\hline \multicolumn{4}{|l|}{$\mathrm{HbA}_{1 \mathrm{c}}[\%]$} \\
\hline Oxidative stress parameters & Autoantibody levels & Apolipoprotein profile & $\begin{array}{c}\text { Inflammatory cytokine } \\
\text { profile }\end{array}$ \\
\hline DNA sequencing & & & \\
\hline
\end{tabular}


concomitant diseases. We will also derive a genetic risk score for CVD and cardiometabolic diseases. Additionally, we will make clinical diagnoses of familial hypercholesterolaemia by identifying causative variants.

\section{Follow-up}

We expect complete or near complete four-year follow-up data for the enrolled patients. We will determine the association between baseline characteristics and laboratory tests with long-term outcome regarding mortality, hospitalisation, occurrence of stroke, and acute coronary syndromes.

\section{Discussion}

LIPIDOGRAM2015 and LIPIDOGEN2015 assess the prevalence of dyslipidaemia and other cardiovascular risk factors in 2015/2016 as a follow-up to the previous LIPIDOGRAM cohort studies started in 2004, consequently giving the perspective of CVD risk factor distribution changes in a more than 10-year perspective [5-7]. In many countries a worrisome trend towards more frequent occurrence of dyslipidaemia, obesity, and diabetes is being observed $[42,43]$. A comparison of data from LIPIDOGRAM2015 with previous editions will enable us to analyse those trends; we will also be able to estimate how many patients reach LDL targets in primary and secondary prevention of cardiovascular disease, and whether it has changed over the last decade. In populations from various countries it was shown that no more than $30 \%$ of patients reach LDL target levels both in primary and secondary prevention of CAD [44-47]. This type of epidemiological data may influence dyslipidaemia treatment guidelines for PHC, but are also of great importance not only for Polish family physicians, but also for cardiologists to whom patients are referred for consultations [48]. Furthermore, public health specialists, medical care administrators, and the public health care payer (NFZ - Polish National Health Fund) managing and financing the health care system will also benefit. Health politicians who plan changes in the health care system in Poland will have the ability to make use of project's results.

The LIPIDOGEN2015 sub-study also allows us to assess the apolipoprotein and inflammatory cytokine profile, enzymatic and non-enzymatic parameters associated with oxidative stress, selected parameters of the immune response, prevalence of antinuclear autoantibodies and antibodies against citrullinated protein/peptide antigens (ACPA), as well as genetics of lipid disorders and susceptibility to CVD and cardiometabolic and atherosclerotic diseases in a large Polish population. Low-grade inflammation and oxidative stress play a role in the pathogenesis of diabetes mellitus and coronary artery disease $[49,50]$. The LIPIDOGEN sub-study, will enable us to analyse inflammatory cytokine profiles and oxidative stress in the context of ASCVD and diabetes mellitus as well as the concomitant diseases.

Autoantibodies are an essential finding in rheumatological diseases, which substantially increase the risk of coronary artery disease in affected individuals. ANA are, however, present in up to $30 \%$ of patients without any diagnosed rheumatological disease [51, 52], and the presence of ANA and CCP has been shown to be associated with CV events in patients with and without rheumatological diseases [53]. The presence of ANA corelates with markers of inflammation, but not with classical CV risk factors, which might implicate different pathophysiological pathways in the progression of atherosclerosis mediated, at least in part, by ANA [51, 52]. Based on our best knowledge, such large cohort population studies, like LIPIDOGEN2015 substudy, for the prevalence of ANA, DFS70, CCP, and CEP- $1 \alpha$ antibodies have not yet been carried out in the Polish population. We hope that ours will also be of importance in planning studies assessing causal relationship between autoimmunological diseases, inflammation, and atherosclerosis.

In addition, 4-year follow-up data on mortality, hospitalisations, occurrence of cardiovascular outcomes, including acute coronary syndromes, and stroke will allow us to draw conclusions on factors affecting prognosis in the LIPIDOGRAM population. In the LIPIDOGEN2015 sub-study we will be able to include in the survival analysis unique laboratory data on apolipoprotein and cytokine profiles, oxidative stress parameters, and the presence of ANA, DFS70, CCP, and CEP- $1 \alpha$ antibodies. Therefore, we believe that the results of the study will be not only of national, but also of international importance. They will allow a comparison of the situation in Poland with other countries in Europe and around the world [54, 55].

The main limitation of this study comes from its observational design; therefore, definite causal inferences will not be possible. Patient recruitment through primary care channels may lead to overrepresentation of patients burdened with concomitant diseases; however, the inclusion criteria were very broad. From previous editions of the LIPIDOGRAM study, we know that the prevalence of classical risk factors is similar to that of other epidemiological studies carried out in Poland [5-7]. In conclusion, the LIPIDOGRAM2015 and LIPIDOGEN2015 studies are the first and among the most important evaluating the distribution of cardiovascular risk factors in consecutive patients in a primary care setting. These studies also assesses the relationship between inflammation, oxidative stress, and mutations in genes coding proteins in- 
volved in lipid metabolism as well as genes conferring susceptibility to CVD and cardiometabolic diseases. These studies might make a critical contribution regarding the role of gene-environment interaction in the development of CV and related diseases.

\section{Acknowledgments}

We would like to thank all the volunteer LIPIDOGRAM2015 and LIPIDOGEN2015 investigators (listed at the end of the paper), all volunteer staff, and all participants.

The present study was an initiative of the Polish Lipid Association (PoLA) and the College of Family Physicians in Poland (CFPiP). The present study was funded by an unrestricted educational grant from Valeant. As a supporter of the study, Valeant played no role in the study design, data analysis, data interpretation, or writing of the report. The present study was also supported by Silesian Analytical Laboratories (SLA, Katowice, Poland), CHDE Poland (Rzeszow, Poland), BIO-RAD (California, USA) and Euroimmun Medizinische Labordiagnostika AG (Lübeck, Germany).

\section{Conflict of interest}

J has received research grant/support from Valeant and has served as a consultant or speaker for Valeant, Amgen, Teva, Servier, Boehringer Ingelheim, Celgene, Bioton, Microlife, and ALAB Laboratories. MB has received research grant(s)/ support from Sanofi and Valeant and has served as a consultant for Akcea, Amgen, Daiichi-Sankyo, KRKA, MSD, Mylan, Polfarmex, Polpharma, Sanofi-Aventis, Servier, Esperion, and Resverlogix. SK has served as a speaker for Novartis. GYHL: Consultant for Bayer/Janssen, BMS/Pfizer, Medtronic, Boehringer Ingelheim, Novartis, Verseon, and Daiichi-Sankyo, and Speaker for Bayer, BMS/Pfizer, Medtronic, Boehringer Ingelheim, and Daiichi-Sankyo. No fees were directly received personally. DPM has given talks, acted as a consultant, or attended conferences sponsored by Amgen, Novo Nordisk, and Libytec. PPT has served as a speaker for Amarin, Amgen, Esperion, Novo-Nordisk; consultant to Amarin, Amgen, Novartis, Resverlogix, and Theravance. TT has served as a consultant or speaker for Boehringer Ingelheim, Novartis, Shire, Biofarm, and Eli Lilly.

**LIPIDOGRAM2015 \& LIPIDOGEN2015 Investigators (listed alphabetically): Al-Shaer B., Andrusewicz W., Andrzejczuk-Rosa M., Anusz-Gaszewska E., Bagińska A., Balawajder P., Bańka G., Barańska-Skubisz E., Barbara Przyczyna B., Bartkowiak S., Bartodziej J., Bartosiewicz M., Basałyga M., Batyra A., Bąk A., Bednarz M., Bejnar K., Bernacki W.,
Betiuk-Kwiatkowska M., Biegaj S., Bień M., Bilski W., Biłogan M., Biruta-Pawłowska G., Biskup A., Błaszczyk B., Błaszczyk H., Błońska-Jankowska T., Bogacka-Gancarczyk B., Bojanowska M., Bonda E., Borowik-Skwarek J., Borowska J., Bruckner J., Brzostek J., Brzuchacz M., Budzyńska M., Bulzacka-Fugiel I., Bulzak J., Bunikowski K., Cebulska A., Celka T., Cempel-Nowak E., Chechliński W., Chludzińska A., Chmiel D., Chmielewska M., Cichy M., Ciemięga A., Ciepluch A., Cieszyńska I., Czajka B., Czapla B., Czerner M., Czerwińska B., Czuryszkiewicz W., Daleka E., Dawid Z., Dąbrowska M., Dąbrowska R., Dąbrowski D., Dąbrowski M., Demczyszyn K., Dębowska-Serwińska A., Dmochowski J., Dobrzecka-Kiwior J., Dolanowska E., Dolanowski H., Dołek P., Domagała M., Domański H., Doszel A., Duda D., Dudkowska M., Dudziuk B., Dybciak P., Dymanowski M., Dziadzio-Bolek L., Eicke M., El-Hassan H., Eremus A., Fąferek-Muller M., Figura-Roguska E., Fijałkowska-Kaczmarek I., Flis M., Florczak T., Florczuk M., Foryszewska-Witan E., Frydrych W., Fugiel A., Futyma E., Gaca-Jaroszewicz A., Gajdamowicz I., Ganczarski K., Gatnar A., Gers M., Głowacki A., Głód K., Godula J., Gołąb J., Gołębiewski M., Goszczyńska E., Gościcka K., Górna-Hajduga A., Górny E., Grabowska T., Grabowski R., Graczyk-Duda A., Gromow A., Grudewicz A., Gruszecka J., Gruszka A., Gryboś J., Grzebyk J., Grzechowiak A., Grzesiak D., Grześkowiak T., Guźla A., Hachuła G., Hawel B., Hiltawska H., Honkowicz E., Ignatowicz J., Imielski K., Iwaniura A., Jagieła-Szymala A., Jalć-Sowała M., Janczylik A., Janisz E., Janiszek M., Jankiewicz-Ziobro K., Januszewska K., Jaremek A., Jaros-Urbaniak A., Jarosz J., Jarosz P., Jasiński W., Jezierska-Wasilewska M., Jędraszewski T., Jędrzejowska A., Józefowicz R., Jóźwiak J.J., Juźwin K., Kacprzak E., Kaczmarek-Szewczyk J., Kaczmarzyk M., Kandziora R., Kaniewski C., Karolak-Brandt L., Kasperczyk S., Kasperek-Dyląg E., Kedziora I., Kępa A., Kiciński J., Kielak-Al-Hosam J., Kiełczawa Ł., Kilimowicz P., Kitliński K., Kiwka T., Klein U., Klichowicz L., Klimowicz A., Klonowski B., Kmolek B., Kobyłko-Klepacka E., Kocoń A., Kolenda A., Kollek E., Kopeć M., Koper-Kozikowska B., Koralewska J., Korczyńska M., Korzeniewski M.T., Kosk A., Kotarski K., Kowalczyk E., Kowalczyk M., Kowalik I., Kozak-Błażkiewicz B., Kozik M., Kozłowska D., Kozłowska E., Kozłowska M. Kozubski T., Kózka K., Kraśnik L., Krężel T., Krochmal B., Król B., Król G., Król J., Królikowska T., Kruszewska H., Krygier-Potrykus B., Krystek W., Krzysztoń J., Kubicki T., Kuczmierczyk-El-Hassan A., Kuczyńska-Witek W., Kujda D., Kurowski A., Kurzelewska-Solarz I., Kwaczyńska M., Kwaśniak M. Kwaśniak P., Kwietniewska T., Łebek-Ordon A., Lebiedowicz A., Lejkowska-Olszewska L., Lentas M., Lesiewicz-Ksycińska A., Limanowski M., Łoniewski S., Łopata J. A., Łubianka B., Łukasiuk I., 
Łużna M., Łysiak M., Łysik B., Machowski Z., Maciaczyk-Kubiak J., Mackiewicz-Zabochnicka G. Magner-Krężel Z., Majda S., Malinowski P., Mantyka J., Marchlik E., Martyna-Ordyniec G., Marzec J., Marzec M., Matejko-Wałkiewicz R., Mazur M., Michalczak M., Michalska-Żyłka A., Michniewicz M., Mika-Staniszewska D., Mikiciuk E., Mikołajczak T., Milewski J., Miller E., Misiaszek B., Mizik-Łukowska M., Młyńczyk-Pokutycka E., Mocek M., Moczała M., Morawska-Hermanowicz M., Moryc P., Moskal A., Moskal S., Moździerz A., Moździerz P., Mrozińska M., Mrozowicz K., Mróz G. Munia T., Mura A., Muras-Skudlarska M., Murawska E. Z., Murawski Ł., Murawski R., Musielak R., Nadaj K., Nagarnowicz W., Napierała R., Niedźwiecka M., Niemirski A., Nikiel J., Nosal M., Nowacki W., Nowak J., Nyrka M., Obst A., Ochowicz J., Ogonowska E., Oleszczyk M., Ołdakowski A., Ołowniuk-Stefaniak I., Ordowska-Rejman J., Orliński M., Osińska B., Ostańska-Burian A., Paciorkowska A., Paczkowska U., Paluch L., Pałka L., Paszko-Wojtkowska J., Paszkowska A., Pawlak-Ganczarska E., Pawlik W., Pawłowska I., Paździora M., Permiakow G., Petlic-Marendziak A., Piasecka T., Piaścińska E., Piktel A., Pilarska-lgielska A., Piotrkowska A., Piwowar-Klag K., Planer M., Plewa J., Płatkiewicz P., Płonczyńska B., Podgórska A., Polewska M., Porębska B., Porwoł P., Potakowska I., Prokop A., Przybylski J., Przybyła M., Psiuk H., Ptak K., Puzoń G. Rabiza N., Rachwalik S., Raczyńska E., Raniszewska M., Romanek-Kozik A., Rosa A., Rosa K., Rozewicz A., Rudzka-Kałwak J., Rusak J., Rutkowska D., Rybacki M., Rybińska D., Rycyk-Sadowska A., Rynda L., Rynkiewicz B., Sadowska-Krawczyk B., Sadowska-Zarzycka M., Sarnecka B., Sawalach-Tomanik E., Sidor-Drozd B., Siemieniak-Dębska M., Sieroń A., Siewniak-Zalewska B., Sikora A., Sitarska-Pawlina B., Skorupski J., Skrzypińska-Mansfeld I., Skubisz J., Skwarek R., Słodyczka M., Smentek M., Smolińska K., Solarz B., Sosnowska W., Sroka B., Stachura H., Stangreciak D., Staniak M., Stańczyk Z., Stańszczak-Ozga D., Startek E., Stefańczyk M., Stelmach R., Sternadel-Rączka E., Sternik M., Stępień J., Stocka J., Stokowska-Wojda M., Studler-Karpińska M., Suchorukow W., Sufryd W., Supłacz B., Sygacz J., Szczepański Ł., Szkandera J., Szłapa-Zellner J., Szydlarska D., Śliwa T., Śliwka J., Śmiejkowski Ł., Targońska A., Tesarska E., Tobiasz M., Tomaka J., Tomalska-Bywalec K., Tomiak E., Topczewski S., Trawińska A., Trela-Mucha L., Trojanowski D., Trzaskowska M., Trzcińska-Larska B., Trznadel-Mozul A., UlanickaLiwoch K., Urbanowicz M., Uthke-Kluzek A., Waczyński J., Walczak J., Warsz L., Wasyńczuk M., Wąchała-Jędras U., Wąsowicz D., Wczysła J., Wenda F., Werner-Kubicka E., Weryszko E., Węgrzynowska B., Wiaksa M., Wiankowski M., Wicherek A., Wieczorek R., Wiencek R., Wienzek-Tatara G., Wierz- bicka B., Wierzbicki M., Wilczyńska B., Wilmańska D., Winiarski P., Wiszniewska-Pabiszczak A., Witkowska M. B., Witzling J., Wlaź A., Wojtkowiak I., Woydyłło J., Woźniak K., Wójtowicz A., Wrona J., Wrońska M., Wujkowska H., Wyrąbek J., Wysokiński O., Zakrzewski R., Zaleska-Zatkalik J., Zaleski J., Zalewska-Dybciak M., Zalewska E., ZalewskaUchimiak B., Zawadzka-Krajewska J., Zawadzki J., Zieliński A., Zubrycka E., Żybort I., Żymełka M.

\section{References}

1. Incalza MA, D’Oria R, Natalicchio A, Perrini S, Laviola L, Giorgino F. Oxidative stress and reactive oxygen species in endothelial dysfunction associated with cardiovascular and metabolic diseases. Vascul Pharmacol 2018; 100: 1-19.

2. Khan MF, Wang G. Environmental agents, oxidative stress and autoimmunity. Curr Opin Toxicol 2018; 7 : 22-7.

3. Adam S, Mohammad JB, Ho JH, et al. Hypercholesterolaemia - practical information for non-specialists. Arch Med Sci 2018; 14: 1-21.

4. Quispe R, Hendrani AD, Baradaran-Noveiry B, et al. Characterization of lipoprotein profiles in patients with hypertriglyceridemic Fredrickson-Levy and Lees dyslipidemia phenotypes: the very large database of Lipids studies 6 and 7. Arch Med Sci 2019; 15: 1195-202.

5. Tomasik T, Jozwiak J, Windak A, et al. Prevention of coronary heart disease in primary medical care in Poland: results from the LIPIDOGRAM study. Eur J Cardiovasc Prev Rehabil 2011; 18: 287-96.

6. Kaess BM, Jóźwiak J, Nelson CP, et al. The relation of rapid changes in obesity measures to lipid profile - insights from a nationwide metabolic health survey in 444 Polish cities. PLoS One 2014; 9: e86837.

7. Kaess BM, Jozwiak J, Mastej $M$, et al. Association between anthropometric obesity measures and coronary artery disease: a cross-sectional survey of 16657 subjects from 444 Polish cities. Heart 2010; 96: 131-5.

8. Smallwood MJ, Nissim A, Knight AR, Whiteman M, Haigh R, Winyard PG. Oxidative stress in autoimmune rheumatic diseases. Free Radic Biol Med 2018; 125: 3-14.

9. Husain K. Inflammation, oxidative stress and renin angiotensin system in atherosclerosis. World J Biol Chem 2015; 6: 209-17.

10. Yang ML, Doyle HA, Clarke SG, Herold KC, Mamula MJ. Oxidative modifications in tissue pathology and autoimmune disease. Antioxidants Redox Signal 2018; 29: 1415-31.

11. Kannan S. Free radical theory of autoimmunity. Theor Biol Med Model 2006; 3: 22.

12. Valko M, Leibfritz D, Moncol J, Cronin MTD, Mazur M, Telser J. Free radicals and antioxidants in normal physiological functions and human disease. Int J Biochem Cell Biol 2007; 39: 44-84.

13. Ahsan H, Ali A, Ali R. Oxygen free radicals and systemic autoimmunity. Clin Exp Immunol 2003; 131: 398-404.

14. Sukkar SG, Rossi E. Oxidative stress and nutritional prevention in autoimmune rheumatic diseases. Autoimmun Rev 2004; 3: 199-206.

15. Vasanthi P, Nalini G, Rajasekhar G. Status of oxidative stress in rheumatoid arthritis. Int J Rheum Dis 2009; 12: 29-33. 
16. Hayter SM, Cook MC. Updated assessment of the prevalence, spectrum and case definition of autoimmune disease. Autoimmun Rev 2012; 11: 754-65.

17. Przywara-Chowaniec B, Seget S, Dróżdż M, et al. Evaluation of antioxidant status in selected connective tissue diseases. Ann Acad Medicae Silesiensis 2018; 72: 116-20.

18. Akmatov MK, Röber N, Ahrens W, et al. Anti-nuclear autoantibodies in the general German population: prevalence and lack of association with selected cardiovascular and metabolic disorders-findings of a multicenter population-based study. Arthritis Res Ther 2017; 19: 127

19. Ngo ST, Steyn FJ, McCombe PA. Gender differences in autoimmune disease. Front Neuroendocrinol 2014; 35: 347-69.

20. Salihoglu S, Dogan SC, Kavakci O. Effects of childhood psychological trauma on rheumatic diseases. Eur J Rheumatol 2019; 6: 126-9.

21. Khojah HM, Ahmed S, Abdel-Rahman MS, Hamza AB. Reactive oxygen and nitrogen species in patients with rheumatoid arthritis as potential biomarkers for disease activity and the role of antioxidants. Free Radic Biol Med 2016; 97: 285-91.

22. Katsiki N, Banach M, Mikhailidis DP. Is type 2 diabetes mellitus a coronary heart disease equivalent or not? Do not just enjoy the debate and forget the patient! Arch Med Sci 2019; 15: 1357-64.

23. Morrow DA, De Lemos JA, Sabatine MS, et al. Clinical relevance of C-reactive protein during follow-up of patients with acute coronary syndromes in the Aggrastat-to-Zocor Trial. Circulation 2006; 114: 281-8.

24. Osadnik T, Pawlas N, Lonnie $M$, et al. Family history of premature coronary artery disease (P-CAD) a non-modifiable risk factor? Dietary patterns of young healthy offspring of P-CAD patients: a case-control study (MAGNETIC Project). Nutrients 2018; 10: E1488.

25. Franzago M, Santurbano D, Vitacolonna E, Stuppia L. Genes and diet in the prevention of chronic diseases in future generations. Int J Mol Sci 2020; 21: 2633.

26. Rukh G, Sonestedt E, Melander O, et al. Genetic susceptibility to obesity and diet intakes: association and interaction analyses in the Malmö Diet and Cancer Study. Genes Nutr 2013; 8: 535-47.

27. Shukla H, Mason JL, Sabyah A. Identifying genetic markers associated with susceptibility to cardiovascular diseases. Futur Sci OA 2019; 5: FSO35.

28. Udler MS, McCarthy MI, Florez JC, Mahajan A. Genetic risk scores for diabetes diagnosis and precision medicine. Endocr Rev 2019; 40: 1500-20.

29. Levin MG, Rader DJ. Polygenic risk scores and coronary artery disease. Circulation 2020; 141: 637-40.

30. Erel O. A novel automated direct measurement method for total antioxidant capacity using a new generation, more stable ABTS radical cation. Clin Biochem 2004; 37 277-85.

31. Södergren E, Nourooz-Zadeh J, Berglund L, Vessby B. Re-evaluation of the ferrous oxidation in xylenol orange assay for the measurement of plasma lipid hydroperoxides. J Biochem Biophys Methods 1998; 37: 137-46.

32. Jain SK. In vivo externalization of phosphatidylserine and phosphatidylethanolamine in the membrane bilayer and hypercoagulability by the lipid peroxidation of erythrocytes in rats. J Clin Invest 1985; 76: 281-6.

33. Koster JF, Biemond P, Swaak AJG. Intracellular and extracellular sulphydryl levels in rheumatoid arthritis. Ann Rheum Dis 1986; 45: 44-6.

34. Ohkawa H, Ohishi N, Yagi K. Assay for lipid peroxides in animal tissues by thiobarbituric acid reaction. Anal Biochem 1979; 95: 351-8.
35. Oyanagui Y. Reevaluation of assay methods and establishment of kit for superoxide dismutase activity. Anal Biochem 1984; 142: 290-6.

36. Erel O. A new automated colorimetric method for measuring total oxidant status. Clin Biochem 2005; 38 1103-11.

37. Solnica B, Sygitowicz G, Sitkiewicz D, et al. 2020 Guidelines of the Polish Society of Laboratory Diagnostics (PSLD) and the Polish Lipid Association (PoLA) on laboratory diagnostics of lipid metabolism disorders. Arch Med Sci 2020; 16: 237-52.

38. Aebi H. Catalase in vitro. Methods Enzymol 1984; 105: 121-6.

39. Paglia DE, Valentine WN. Studies on the quantitative and qualitative characterization of erythrocyte glutathione peroxidase. J Lab Clin Med 1967; 70: 158-69.

40. Habig WH, Jakoby WB. Assays for differentiation of glutathione S-transferases. Methods Enzymol 1981; 77: 398-405.

41. R Core Team. R: A Language and Environment for Statis tical Computing. Published online 2019

42. Danaei G, Finucane MM, Lu Y, et al. National, regional, and global trends in fasting plasma glucose and diabetes prevalence since 1980: systematic analysis of health examination surveys and epidemiological studies with 370 country-years and 2.7 million participants. Lancet 2011; 378: 31-40.

43. Cheng $\mathrm{Y}$, Yin $\mathrm{H}$, Zheng $\mathrm{H}$, et al. Time trend of cardiometabolic risk factors over a 10 -year period in the office-working population in China. BMJ Open 2019; 9 e025915.

44. Jankowski P, Czarnecka D, Badacz L, et al. Practice setting and secondary prevention of coronary artery disease. Arch Med Sci 2018; 14: 979-87.

45. Liberopoulos E, Rallidis L, Spanoudi F, et al. Attainment of cholesterol target values in Greece: results from the Dyslipidemia International Study II. Arch Med Sci 2019 15: 821-31

46. Dyrbus K, Gasior M, Desperak P, Nowak J, Osadnik T, Banach M. Characteristics of lipid profile and effectiveness of management of dyslipidaemia in patients with acute coronary syndromes - data from the TERCET registry with 19,287 patients. Pharmacol Res 2019; 139: 460-6.

47. Kones R. Primary prevention of coronary heart disease: Integration of new data, evolving views, revised goals, and role of rosuvastatin in management. A comprehensive survey. Drug Des Devel Ther 2011; 5: 325-80.

48. Banach M, Burchardt P, et al. PoLA/CFPiP/PCS/PSLD/PSD/ PSH guidelines on diagnosis and therapy of lipid disorders in Poland 2021. Arch Med Sci 2021; 17: 1447-547.

49. Karam BS, Chavez-Moreno A, Koh W, Akar JG, Akar FG. Oxidative stress and inflammation as central mediators of atrial fibrillation in obesity and diabetes. Cardiovasc Diabetol 2017; 16: 120.

50. Halim M, Halim A. The effects of inflammation, aging and oxidative stress on the pathogenesis of diabetes mellitus (type 2 diabetes). Diabetes Metab Syndr Clin Res Rev 2019; 13: 1165-72.

51. Solow EB, Vongpatanasin W, Skaug B, Karp DR, Ayers C, de Lemos JA. Antinuclear antibodies in the general population: positive association with inflammatory and vascular biomarkers but not traditional cardiovascular risk factors. Clin Exp Rheumatol 2018; 36: 1031-7.

52. Akmatov MK, Röber N, Ahrens W, et al. Anti-nuclear autoantibodies in the general German population: prevalence and lack of association with selected cardiovas 
cular and metabolic disorders-findings of a multicenter population-based study. Arthritis Res Ther 2017; 19: 127.

53. Liang KP, Kremers HM, Crowson CS, et al. Autoantibodies and the risk of cardiovascular events. J Rheumatol 2009; 36: 2462-9.

54. NCD Risk Factor Collaboration (NCD-RisC). National trends in total cholesterol obscure heterogeneous changes in HDL and non-HDL cholesterol and total-toHDL cholesterol ratio: a pooled analysis of 458 population-based studies in Asian and Western countries. Int J Epidemiol 2020; 49: 173-92.

55. Krzemień P, Kasperczyk S, Banach $M$, et al. Relationship between anti-DFS70 autoantibodies and oxidative stress. Biomark Insights 2022; 17: 11772719211066791 


\section{Appendix S1}

lipidogram \& 2015 \& lipidogen 2015

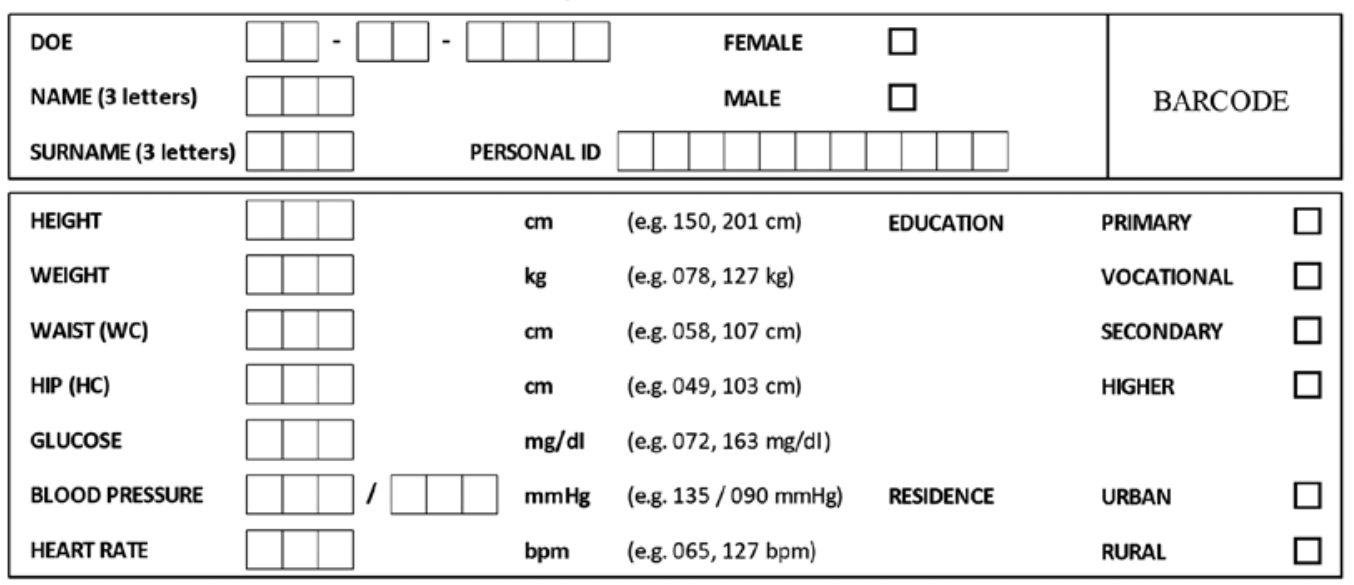

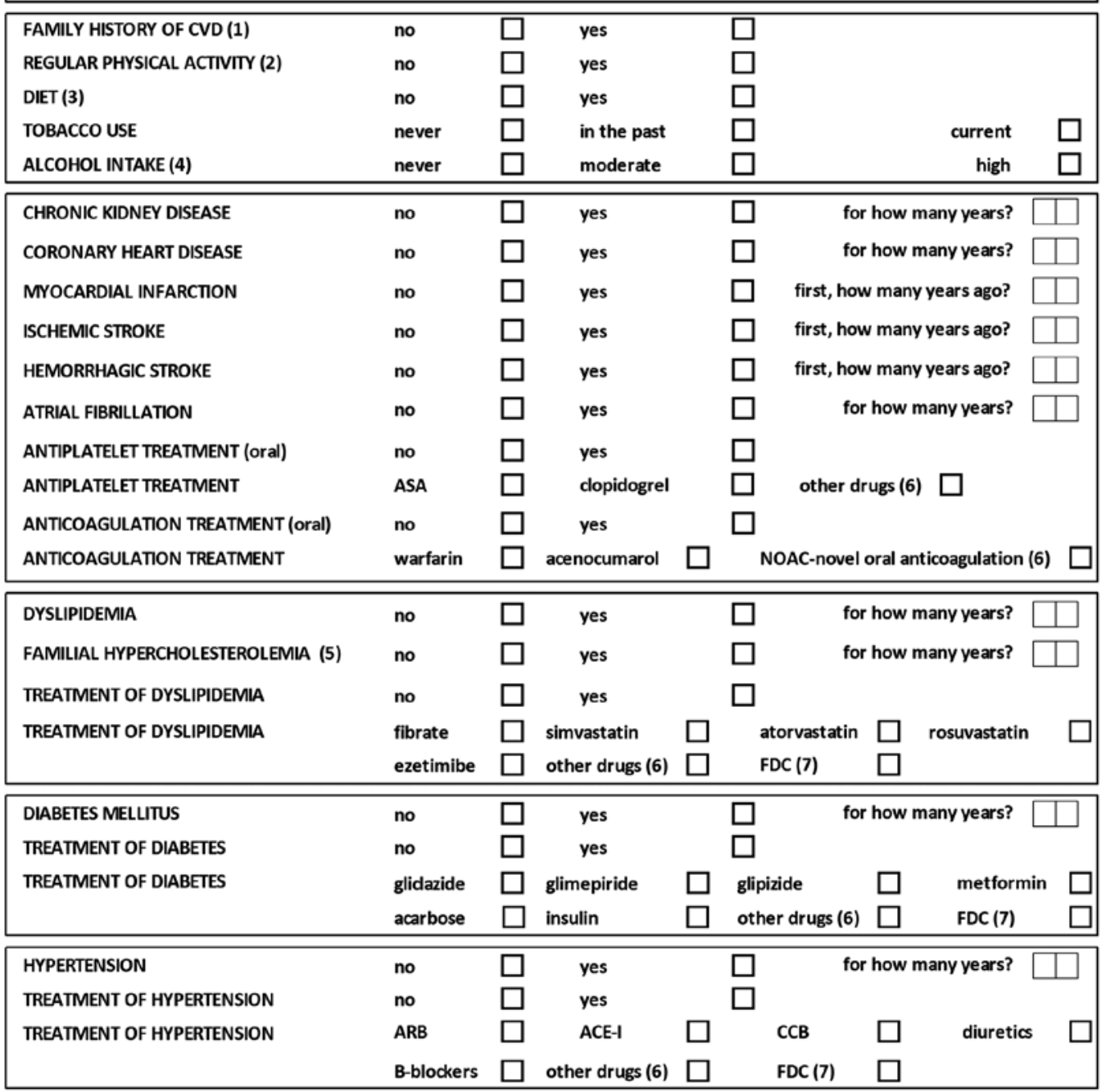

